directors should be given as much freedom as possible in administration, with more time to exereise scientific guidance; the number of research committees-at present twenty-five-should be kept within bounds, and committees should be terminated when their work does not warrant two or three meetings a year; and further consideration of the relations between the national laboratories and institutes and the universities is recommended so as to ensure that the whole scientific organization oporates in concert.

There are sensible suggestions for co-operation in this field, including the interchange of facilities and of staff and welcoming the establishment of a University Grants Commission to provide grants for ensuring salary scales to attract staff of high quality, and the Committee stresses the importance of encouraging research at the universities and higher technological institutes. Emphasizing equally the importance of co-operation with industry, it recommends that the liaison officer at the Council's headquarters should be responsible for furthering all such collaboration between the Council's institutes and laboratories and other research organizations. Special attention is directed to the need for closer coordination and co-operation between the Council and the medical and agricultural research services, and more active co-operation with government departments is also recommended to facilitate utilization of the results of research carried out under the Council. For the same purpose, as much help as possible should be given to the National Research Development Corporation, and the institutes should be assisted to establish pilot plants.

The Reviewing Committee favours the establishment of further research associations where the size of an industry would justify this procedure, and it is obvious that, with regard to the utilization of research results, the dissemination of information, development and the formulation of research programmes, experience in India is not dissimilar from that in Britain. The Committee's remarks as to the way in which the Council could give the measure of direction to the research done under its æais necessary to ensure that it is related to India's needs and to the general advance of science are of considerable interest. Ideas, it recognizes, must come mainly from the centres of research and, as research programmes, or less formally, they are discussed at meetings of the Council's resoarch committees. At this stage they should be related to the general plan for India and to the state of science and technology; and the Reviewing Committee suggests that the principal executive officer and director of the Council should be able to call together such members of the Advisory Board, directors and advisory committees of the laboratories and others from medical or agricultural research or the universities as would be needed to assess the importance and priority of particular ideas, and to suggest suitable laboratories within or without the organization where the research could be initiated. He would thus be enabled to present to the Advisory Board of the Council $a$ directive in relation to the programme which is submitted to the Board for review at least twice a year.

The developments which the Reviewing Committee considers desirable to complete the Council's cover of India's requirements are the Institute of Mining Research and the Central Mechanical Engineering Research Institute, both of which are to be established, the latter at Calcutta, mainly through private benefaction, and in this connexion the Committee comments on the need to attract young engineers to undertake research. It has also been agreed to accommodate a Telecommunications Research Institute in the National Physical Laboratory, where the Defence Science Laboratory is also temporarily housed. It recommends that full opportunities should be given for astronomical research in India, so as to utilize the ability for mathematical analysis and physical investigation for which Indian scientific workers are particularly noted, and that the Council should at least foster astronomical research in the universities and other centres. The proposal to establish meteorological stations is welcomed and $\mathbf{a}$ centre for geophysical research is also recommended.

Provision for atomic energy is regarded as adequate, but some concentration of research effort on the utilization of solar energy, either direct or by chemical or biochemical means, is recommended, as well as further attention to the de-salination of water and concerted efforts to conserve, improve and recover the soils of India. Physiological research requires full attention, and genetics also needs adequate cover. The Committee concludes its report with a tribute to the work already accomplished in so short a time and to the ability of the Council's chief executive officer, Sir Shanti Bhatnagar.

\section{DEEP-WATER MOVEMENTS IN THE OCEAN}

$\mathrm{M}$ $\mathrm{UCH}$ less is known about water movements in the depths of the oceans than about surface currents. The oceanic circulations, however, involve movements of water at all levels, with vertical as well as horizontal components, so that the movements in the various layers are to some extent dependent on one another. Deep-water movements are therefore of interest to meteorologists as well as to marine physicists, biologists and geologists.

A Geophysical Discussion on this subject took place at a meeting of the Royal Astronomical Society on October 22. Dr. G. E. R. Deacon (National Institute of Oceanography), who was in the chair, referred to a quotation from Croll, towards the end of the past century, to the effect that the cause of ocean eirculations was a question belonging to the domain of physics and mechanies, whereas few physicists or mathematicians of note had given much attention to it ; this, he said, is no longer true. The contributions to the Discussion, continued Dr. Deacon, would show evidence of various ways in which problems of oceanic circulation are being tackled theoretically and by laboratory experiments as well as by observations in the oceans themselves.

In the first paper, Prof. K. F. Bowden (University of Liverpool) gave a brief account of the main features of the oceanic circulation below the surface layers, as deduced from the observed distributions of temperature, salinity, oxygen content and other properties. He referred to various estimates which have been made of the velocities of the deep-water movements, such as those based on the balance between horizontal flow and vertical or lateral mixing, and particularly to the charts of currents at $800 \mathrm{~m}$. and $2,000 \mathrm{~m}$. in the Atlantic Ocean deduced by Defant on the basis of the absolute dynamic topography. Most estimates agree in order of magnitude, giving the velocity of flow of the Antarctic 
Bottom Water, for example, as about $1 \mathrm{~cm} . / \mathrm{sec}$. , so that it would take about twenty years to travel from the Antaretic to the Equator. Estimates by carbon-14 dating technique, however, have given a time as long as eighteen hundred years, while photographs of sand ripples have suggested currents greater than $15 \mathrm{~cm}$. $/ \mathrm{sec}$. at the bottom. The direct measurements which have been made to date have been in some cases in agreement and in others in disagreement with the estimates. The difficulties of using a current meter from an anchored ship lead to possible errors of measurement which may, in some cases, be comparable with the deep currents themselves. New methods and techniques, some examples of which were given by subsequent speakers, are needed in the study of deep currents.

The next two papers were of a theoretical character, and both were concerned with currents due directly or indirectly to the stress of the wind on the sea surface. Dr. E. T. Eady (Imperial College of Science and Technology, London) gave a critical account of recent theories of the wind-driven large-scale circulations, which have shown that the concentration of flow towards the western sides of the oceans arises as a consequence of the variation of the vertical component of the earth's rotation with latitude. The basis of such theories, as developed by Stommel and Munk, is the integrated vorticity equation, from which it may be inferred that, in a steady state and in the absence of stresses on the 'sides' of a vertical column of water due to turbulent motion, the mean northsouth motion of the column is proportional to the external torque, presumably due almost entirely to wind stresses on the surface of the ocean. The reason is that the rate of (absolute) rotation of the column must be almost the same as the vertical component of the earth's rotation, and this increases with latitude. Since the external torque is mainly a function of latitude and all the water cannot move north or south, it is necessary to assume that short-range turbulent stresses play an important part in a narrow region on the western side of the ocean, where there is a strong narrow current in the opposite direction to the drift elsewhere. A difficulty in interpretation is that we do not know the mean currents, measurements of density gradient yielding only relative currents. As a step towards a more detailed theory, Dr. Eady showed that, if we suppose that the turbulent motion which transmits the surface stresses downwards is limited to a rather shallow layer, then there must be convergence in this layer near latitude $30^{\circ}$ which forces down the light surface water. There are, however, difficulties in applying such a simple theory in low latitudes.

Dr. W. V. R. Malkus (Woods Hole Oceanographic Institution, U.S.A.) gave an account of a treatment representing an extension of work by $H$. Stommel, which was based on the assumption of a two-layer ocean, considering particularly its application to the Gulf Stream. The two layers, of different temperatures, and hence of different densities, are separated by an interface of variable depth which meets the surface in a line corresponding to the cold northern edge of the Gulf Stream. The surface layer is assumed to be in geostrophic balance and its vorticity conserved. Dr. Malkus gave a solution for the depth of the upper layer as a function of latitude and the transport by the current in the upper layer for a given distribution of wind stress. He suggested that momentum is lost from the Gulf Stream by eddies which break off from the meanders, the momentum being dissipated in the cold water to the north of the current and the heat lost by radiation and evaporation to the atmosphere. Assuming that half the momentum of the Gulf Stream is lost in this way, and taking the appropriate temperatures for the two layers, a reasonable solution may be obtained for the loss of heat energy and for the depth of the interface. For a transport corresponding to the wind stress curl as observed, the maximum depth is $800 \mathrm{~m}$. Dr. Malkus suggested further that the water lost from the surface layer in this way returns as a deep current, with a velocity which would be about $1 \mathrm{~cm}$. $/ \mathrm{sec}$. if distributed over $3,000 \mathrm{~m}$. of depth. This might be re-incorporated in the surface layer in lower latitudes by the deepening of the thermocline by about $50 \mathrm{~m}$., which occurs in the winter months.

Mr. T. V. Davies (King's College, London) dealt with a possible experimental approach on the model scale, referring to the 'dish pan' experiments of Fultz in Chicago and Hide in Cambridge, which were designed to study motions in the atmosphere on the rotating earth. In the experiments, a liquid is contained in the annular space between two concentric cylinders, which are rotated about their common axis. Heat is supplied at the outer boundary while the inner boundary is cooled, corresponding to the heating of the atmosphere in the equatorial region and cooling near the poles. The flow régime depends, other things being equal, on the angular velocity of rotation. For low rates of rotation, the water particles rise near the outer boundary, move inwards near the surface, sink near the inner boundary and flow outwards below in a uniform manner. This has been called the 'Hadley régime'. When the rate of rotation exceeds a critical value, another system of flow, known as the 'Rossby régime', sets in, in which the surface flow becomes concentrated into wave-like paths, similar to the 'jet streams' which occur in the upper atmosphere. Mr. Davies presented the theory on which these experiments are based, starting from the equations of motion, continuity and heat transfer, and arriving at three parameters governing the motion, by which the transformation from model to full-scale flow should be carried out. The values of these parameters for the ocean are of the order of a hundredth of those for the atmosphere, but they should be within the range readily attainable in experiments. The type of motion studied hitherto derives its energy from thermodynamic processes, which are predominant in the atmosphere. Mr. Davies pointed out that the surface stresses, which are important in the case of the oceans, have not been represented, but suggested that they might be included by using two layers of liquid in the experiments.

In the last contribution, Mr. J. Crease (National Institute of Oceanography) returned to full-scale observations in the ocean, describing some results obtained by three different methods during last May and June in R.R.S. Discovery II, working in an area between Spain and the Azores, about $42 \frac{1}{2}^{\circ} \mathrm{N}$., $20 \frac{1}{2}^{\circ}$ W., in a depth of about $4,000 \mathrm{~m}$. In the first method, a deep drogue constructed of two steel frames $6 \mathrm{ft}$. square, in the form of a cross, and covered with canvas, was suspended by piano wire from a pair of small elliptical floats. Two such drogues, one at $1,000 \mathrm{~m}$. and the other at $2,000 \mathrm{~m}$., were tracked for several days, their positions being fixed by radar from the ship, relative to a marker buoy moored by piano wire to a sinker on the bottom. Both indicated 
a flow directed approximately towards the eastnorth-east, the drogue at $1,000 \mathrm{~m}$. averaging about 0.2 knot (about $10 \mathrm{~cm}$. $/ \mathrm{sec}$.) and that at $2,000 \mathrm{~m}$. about 0.1 knot. The second method consisted of taking normal hydrographic stations down to $3,000 \mathrm{~m}$. at the four corners of a square of 10 miles side, and computing the velocity perpendicular to each side of the square relative to that at $3,000 \mathrm{~m}$. The results indicated an apparent flow into the square across one pair of opposite sides and outwards across the other pair of sides. Mr. Crease suggested that this surprising result might be due to tidal changes in the slopes of the isobaric surfaces, the whole four stations having been occupied in a period of a little more than twelve hours. The third method employed a new technique, analogous to the use of an inverted radiosonde. A supersonic transmitter, emitting a 'ping' every few seconds, was attached to a type of parachute, so that it sank slowly through the water at a rate of about $250 \mathrm{~m}$./hr. Its position was fixed at intervals by sound-ranging, the pings being received by four hydrophones, one suspended below the ship and the other three below sono-radio buoys, which were moored to the bottom by piano wire, and which transmitted the received signals to the ship. The relative positions of the buoys and the ship were fixed by radar. The results showed a current in the same direction as that indicated by the drogues, but of a greater magnitude: about $0.5 \mathrm{knot}$ down to 1,200 $\mathrm{m}$. and decreasing at greater depths.

The discussion which followed reflected the interest aroused in the new theoretical and experimental approaches. In reply to suggestions on the sinking transmitter technique, Mr. Crease said that the design of a transmitter which would remain for a long period at a constant depth was being considered. Reference was made to the rotating model experiments of Von Arx at Woods Hole, Massachusetts, in which a basin of paraboloidal shape is used, providing for the variation of Corolis parameter with latitude, and boundaries having the outlines of the actual ocean boundaries in the northern hemisphere are inserted. Air streams over the model simulate the atmospheric wind systems, so that these experiments are a study of the wind-driven ocean circulation and in a sense are complementary to the 'dish pan' experiments, which have been concerned with cir culations arising from processes of heating and cooling. While much remains to be learned about deep-water movements and the part they play in the general occanic circulation, it is clear that the subject is being attacked vigorously from several angles and that encouraging progress is being made.

K. F. BOWDEN

\section{LABORATORY ANIMALS IN THE UNITED STATES}

"T HE need for adequate standards and methods in the procurement of biological materials for research, assaying, testing and teaching"-to quote Dr. Orson N. Eaton--has been recognized for many years. The biological materials referred to are laboratory animals, and the need has, since the Second World War, become pressing in nearly every country in the world. The first action on a national scale was taken by the British Medical Research Council, which set up the Laboratory Animals Bureau in 1947. Five years later, in 1952, the Division of Biology and Agriculture of the American National Research Council, in consultation with government, university and industrial representatives, created an Institute of Animal Resources, and appointed Dr. Eaton as its executive secretary.

This was not the first American organization to make its main purpose the study of problems connected with laboratory animals. In 1950 a private and voluntary group of veterinarians and others interested in the provision and use of animals for scientific work formed an Animal Care Panel. This Panel has met every year from 1950 onwards for the purpose of receiving communications from its members, and these communications, together with the inevitable and stimulating discussions, are reproduced as proceedings. The proceedings are circulated only to members of the Panel, which is unfortunate, for much of their contents deserves wider publication; but the financial resources of the group are limited, and wider publication would presumably be beyond them.

There was a need, therefore, for the Institute of Animal Resources, with its official backing, both moral and material, and the choice of a distinguished geneticist as its executive secretary was a good one. All problems relating to laboratory animals are not genetical, and the Board of the Institute represents many other interests; but as the work of the Institute progresses, genetics will become increasingly important, and it is well that such developments can be expertly anticipated.

The work of the Institute is complementary to that of the Animal Care Panel, and since one finds that many names on the Board of one are among the membership of the other, close collaboration between the two can be assured. In addition to Dr. Eaton as executive secretary, the membership of the Executive Board of the Institute is made up as follows: P. B. Armstrong, Marine Biological Laboratory, Woods Hole; N. R. Brewer, Central Animal Quarters, University of Chicago ; T. C. Byerly, U.S. Department of Agriculture ; G. B. Coursen, General Biological Supply House, Chicago; A. E. Earl, Ciba Pharmaceutical Products; H. G. Herrlein, Rockland Farms; G. E. Jay, jun., National Institutes of Health; D. Jenkins, Chemical Corps Biological Laboratories; G. W. Kidder, Amherst College; C. G. King, Nutrition Foundation; W. Landauer, University of Connecticut; C. C. Little, Jackson Memorial Laboratory; R. C. Percival, Lederle Laboratories; and C. A. Slanetz, College of Physicians and Surgeons, Columbia University.

The aims of the Institute are: (1) to survey and list existing sources of animal stocks used in biological (including agricultural, medical and industrial) research, testing and assaying; and to determine the consumers and the volume of demand for such material ; (2) to perpetuate this activity by taking periodic inventories and keeping a live master registry of those sources, for distribution to all interested persons and groups of consumers (for example, research laboratories, academic institutions, government agencies, industrial and trade establishments, etc.); (3) to promulgate scientific standards of definition, terminology and tolerated variability in regard to genetic constitution, nutrition, freodom from disease, housing conditions and maintenance for the major groups of animals in use; (4) to act as a liaison centre on information regarding the detection, preservation and perpetuation of new or old strains 